\title{
Efficiency of Sulfuric Acid on Selective Scandium Leachability from Bauxite Residue ${ }^{\dagger}$
}

\author{
Maria Ochsenkuehn-Petropoulou *, Lamprini-Areti Tsakanika *, Theopisti Lymperopoulou, \\ Klaus-Michael Ochsenkuehn, Konstantinos Hatzilyberis@ ${ }^{\circledR}$, Paraskevas Georgiou ${ }^{\circledR}$, \\ Chrysanthos Stergiopoulos, Olga Serifi and Fotis Tsopelas ${ }^{(\mathbb{D}}$ \\ School of Chemical Engineering (Chem. Eng.), National Technical University of Athens (NTUA), \\ 9 Iroon Polytechniou St., 15780 Athens, Greece; veralyb@chemeng.ntua.gr (T.L.); \\ klausochsenkuehn@yahoo.com (K.-M.O.); ksh@chemeng.ntua.gr (K.H.); pngche@gmail.com (P.G.); \\ chrisxp3@hotmail.com (C.S.); olga.serifi@gmail.com (O.S.); ftsop@central.ntua.gr (F.T.) \\ * Correspondence: oxenki@central.ntua.gr (M.O.-P.); btsakanika@gmail.com (L.-A.T.); \\ Tel.: +30-210-772-3094 or +30-697-203-5984 (M.O.-P.); +30-210-772-4022 or +30-695-523-9222 (L.-A.T.) \\ † This paper is part of the oral presentation entitled "Mineral Acid Leaching of Scandium from Bauxite \\ Residue", presented by Ochsenkuehn-Petropoulou, M. Proceedings of the International Bauxite Residue \\ Valorization and Best Practices Conference-BR2018, Athens, Greece, 7-10 May 2018. Available online: \\ http:/ /svs2015-mtm.icts.kuleuven.be/indico/event/39/contribution/30 (accessed on 20 September 2018). \\ The whole proceedings are not available online and only a hard copy of them exists.
}

Received: 3 October 2018; Accepted: 5 November 2018; Published: 7 November 2018

\begin{abstract}
Bauxite residue (BR) is a well promising resource for critical metals, especially scandium (Sc), a rare and expensive metal with increasing applications in advanced technology. Greek BR seems to significantly favor a commercially viable recovery of Sc combining optimized leaching and advanced separation techniques. Leaching with mineral acids emerges as the dominant selection compared to other techniques. This study investigates an optimized leaching condition set for Sc recovery, using the most advantageous option of sulfuric acid. The main target is to develop a leaching scale-up process to be established in the premises of Mytilineos S.A. (formerly Aluminium of Greece, the largest Greek alumina and aluminum producer), taking into account the feed requirements of a subsequent advanced ion exchanged procedure. Several parameters were studied individually or combined in order to achieve high Sc concentration in the leachate and to ensure selectivity, especially concerning iron. The most significant parameters prove to be the solid-to-liquid ratio (S/L), the final $\mathrm{pH}$ value, and the leachate's recycling. The proposed process, with low molarities of sulfuric acid and ambient conditions, integrates rapidly, leading to high and selective Sc recovery. Finally, a leaching process flow diagram under continuous operation on an industrial scale is developed.
\end{abstract}

Keywords: bauxite residue; scandium; leaching; sulfuric acid

\section{Introduction}

Bauxite residue $(\mathrm{BR})$, also called red mud, is the highly alkaline $(\mathrm{pH}>11)$ and very fine-grained slurry by-product after "Bayer" process for alumina production. Its huge global annual production of $\sim 120$ million tons [1] has resulted in increasing BR accumulation, causing deposition problems and serious environmental impacts. The management and the safe disposal of this waste are major issues for the bauxite and alumina industries, affecting production cost. The valorization of BR as a secondary raw material and as a metal resource of low cost could be a route for its reduction, introducing the waste again in the economic cycle. BR is rich in minerals and metals of high economical interest. Its chemical composition depends directly on the origin of the bauxite ore and the conditions of the Bayer 
process. It contains oxides and salts of the main elements $\mathrm{Fe}, \mathrm{Al}, \mathrm{Ca}, \mathrm{Na}, \mathrm{Si}$, $\mathrm{Ti}$, numerous trace elements such as $\mathrm{V}, \mathrm{Cr}, \mathrm{Zn}, \mathrm{Ga}, \mathrm{Nb}, \mathrm{Zr}$, and Ta, and rare earths elements (REEs) (Sc, Y, and lanthanides) [2].

In Greece, Mytilineos S.A., formerly “Aluminium of Greece” (AoG), produces annually about 750,000 tons of BR, which is characterized as chemically stable. Besides other metals, Greek BR is rich in REEs, especially in scandium (Sc). It was found to contain $\sim 1 \mathrm{~kg}$ REEs $/ \mathrm{t}$ of dry BR with an Sc content of $\sim 120 \mathrm{~g} / \mathrm{t}$ of dry BR $\left(0.02 \% \mathrm{Sc}_{2} \mathrm{O}_{3}\right)$ close to $\mathrm{Sc}$ main resources. Greek BR is enriched in REEs by a factor of two referring to the original bauxites, and the concentration of REEs is almost constant for a period of about 25 years [2-5]. It is calculated that a full exploitation of Greek BR from AoG can produce about $1 \mathrm{kt} / \mathrm{yr}$ of REEs oxides.

REEs, especially Sc, are elements of high techno-economical interest because of their use in high-tech materials and modern applications. Scandium is exceptionally expensive especially in high purity, presenting highly promising demand but low availability due to its few economically exploitable minerals and its difficult recovery from deposits where co-exists with radioactive elements [6].

European Commission's classification of Critical Raw Materials (CRMs) [7] ranks Sc as critically high on both supply risk and economic importance due to the decreasing available stockpiles combined with the globally limited production and the evolution of new applications [8-16]. The lightweight Al-Sc alloys with a content of $0.5-2 \%$ Sc find applications in the aerospace and defense technology and athletic equipment. Additionally, the use of Sc as an electrolyte in solid oxide fuel cells as a result of its improved oxygen ion conductivity creates the conditions for a sustainable Sc supply route.

The economic value of REEs/t in Greek BR according to recent target prices shows that Sc corresponds to more than $90 \%$ of the total value, rendering its selective recovery attractive for industrial-scale exploitation [17-20].

Hydrometallurgical treatment is the most commonly used technique for REE (including Sc) recovery from BR [21,22]. Several conventional mineral [3,4,17-19,21-29] and organic acids [3,28], as well as alkaline solvents $\left(\mathrm{Na}_{2} \mathrm{CO}_{3}\right)$ [30], have been studied. The use of organic acids shows very low recovery yields, while alkaline solvents hinder the following ion exchange and solvent extraction processes for $\mathrm{Sc}$ isolation and purification [14]. The addition of oxidative additives such as $\mathrm{H}_{2} \mathrm{O}_{2}$ with $\mathrm{H}_{2} \mathrm{SO}_{4}$ has also been investigated [31]. The presence of $\mathrm{H}_{2} \mathrm{O}_{2}$ has a positive effect on Sc recovery and selectivity mainly against $\mathrm{Ti}$ as well as in leachate handling, but the requirement of high temperatures $\left(90{ }^{\circ} \mathrm{C}\right)$ increases operation cost at the expense of method viability. Other researchers [32-34] have tested ionic liquids in BR leaching and bioleaching, but results fall short due to low Sc recovery yield, the requirement for stronger conditions, and the high cost of ionic liquids. Under these drawbacks, the process viability on an industrial scale seems quite uncertain. Concerning bioleaching and the requirement of specific microorganisms for the degradation of BR, there is still much research work to be done. In cases where BR pretreatment is applied prior to leaching such as the pyro-metallurgical roasting or smelting, the need for strong conditions and high-energy consumption limits their economic performance $[35,36]$.

The present work is a continuation of over 20 years of research in REE recovery from BR that resulted in the development of an innovative method for the selective separation and purification of REEs, especially Sc, including nitric acid leaching, ion exchange, selective extraction-backstripping, and HPLC (High Performance Liquid Chromatography) processes [3-5,17-19,23-25,37,38]. The whole procedure has been performed on a lab scale and partially scaled up to a pilot plant with comparable results $[4,24,25]$.

In the present study, acidic leaching of BR using $\mathrm{H}_{2} \mathrm{SO}_{4}$ as a leaching agent was investigated for scandium selective recovery. The selection of sulfuric acid was based on environmental and economic reasons as being of critical importance in industrial-scale applications. Different parameters such as acid molarity, solid-to-liquid ratio (S/L), leaching time, final $\mathrm{pH}$, leaching temperature, stirring mode, multistage leaching of the same BR with fresh acid, and recycling of the leachate solution to fresh BR were tested and evaluated, aiming at high Sc concentration and selective recovery, especially with respect to iron. The results reveal that the proposed process for Sc recovery is rather fast, with 
scandium extraction being completed within less than $60 \mathrm{~min}$, using low concentrations of sulfuric acid $(<3 \mathrm{M})$. The effects of $\mathrm{S} / \mathrm{L}$, the adjustment of final $\mathrm{pH}$, the multistage leaching, and especially the recycling were proven to be critical in achieving scandium recoveries up to $60 \%$ with low $(<10 \%)$ iron impurities. Increasing the leaching temperature enhances iron dissolution resulting in reduced selectivity. The impact of the above parameters was evaluated with respect to Sc concentration in the leachate, since this is the decisive factor for the implementation of any subsequent purification process ([19], Section 3.1). The results were compared to those obtained in previous studies with other mineral acids on lab and pilot plant scales. Sulfuric acid leads to a competent $\mathrm{Sc}$ recovery and selectivity over iron, and it is more economically viable and environmentally friendly than the other investigated mineral acids. A flow diagram for the scale-up of the investigated leaching process on an industrial scale under ambient and environmental friendly conditions is developed taking into consideration the requirements of the leachate for the subsequent ion exchange process for scandium purification.

\section{Materials and Methods}

\subsection{Sample Collection and Characterization}

All experiments were conducted using a BR (red mud) sample produced in December 2016, provided by AoG. Mineralogical analysis of BR was performed by XRD (X-ray Diffraction) (BRUKER, Karlsruhe, Germany) (as shown in Figure S1). The sample had a pH value of 11.3, and a moisture content of about $26 \%$.

\subsection{Leaching Experiments}

The sulfuric acid $\left(\mathrm{H}_{2} \mathrm{SO}_{4}\right)$ used was of industrial grade, 96-98\% w/w (Kalogeropoulos S.A., Athens, Greece).

Leaching experiments were performed adding an appropriate amount of dry BR to 200-2000 mL of 1-3 $\mathrm{M} \mathrm{H}_{2} \mathrm{SO}_{4}$ in order to result in $2-30 \% \mathrm{~S} / \mathrm{L}$ values. For the leaching time effect study, a sample was collected at $5,15,30,45$, and $60 \mathrm{~min}$.

For temperature experiments, $2 \mathrm{M} \mathrm{H}_{2} \mathrm{SO}_{4}$ was preheated at 50 and $80^{\circ} \mathrm{C}$ in conical flasks immersed in water baths on a magnetic stirrer hot plate. An appropriate amount of dry BR was added to the hot $\mathrm{H}_{2} \mathrm{SO}_{4}$, resulting in a $10 \% \mathrm{~S} / \mathrm{L}$, and stirred for $60 \mathrm{~min}$. High temperature experiments were performed in an autoclave, where $2 \mathrm{M} \mathrm{H}_{2} \mathrm{SO}_{4}$ was added to dry $\mathrm{BR}$, resulting in a $10 \% \mathrm{~S} / \mathrm{L}$ in the Teflon vessel. The vessel was introduced in the autoclave bomb and heated at 160 and $230{ }^{\circ} \mathrm{C}$ (hot plate temperature) for 60 min under magnetic stirring.

In the above cases, the final $\mathrm{pH}$ of the leachate was measured, and the leachates were filtered under vacuum with $0.45 \mu \mathrm{m}$ cellulose nitrate membranes supplied by Whatman plc (GE Healthcare Life Sciences, Little Chalfont, UK) and stored for analysis.

Final $\mathrm{pH}$ adjustment of the leachate was performed by the addition of concentrated sulfuric acid to dry $\mathrm{BR}$ in order to achieve a final $\mathrm{pH}$ of the leachate about $0.1-0.2$, and the mixture was stirred up to $60 \mathrm{~min}$. $\mathrm{pH}$ and temperature were monitored by an electronic $\mathrm{pH}-$ meter (multi 350i, by WTW, Weilheim, Germany). The leachates were filtered $(0.45 \mu \mathrm{m}$ under vacuum) and stored for analysis.

For the multistage leaching experimental procedure, an appropriate amount of dry BR was added to 1,2 , and $3 \mathrm{M} \mathrm{H}_{2} \mathrm{SO}_{4}$ in a conical flask, resulting in an $\mathrm{S} / \mathrm{L}$ of 5 and $10 \%$. The mixtures were stirred using a magnetic stirrer for $60 \mathrm{~min}$ at ambient conditions. After leaching and centrifugation procedures, the precipitate was collected and re-treated with fresh $\mathrm{H}_{2} \mathrm{SO}_{4}$, while the supernatant liquid was removed, filtered ( $0.45 \mu \mathrm{m}$ under vacuum), and stored for analysis. The process was repeated thrice. The $\mathrm{pH}$ value of the leachate was measured after each repetition.

The leachate recycling experiments were conducted in a conical flask or a sealed spherical flask by adding an appropriate amount of dry $\mathrm{BR}$ in 1 and $2 \mathrm{M} \mathrm{H}_{2} \mathrm{SO}_{4}$, resulting in an $\mathrm{S} / \mathrm{L}$ of $10 \%$. $\mathrm{pH}$ value was adjusted close to 0 with an appropriate amount of concentrated $\mathrm{H}_{2} \mathrm{SO}_{4}$. After 60 min of magnetic or mechanical agitation, the leachate was collected, filtered $(0.45 \mu \mathrm{m}$ under vacuum), and reused on 
fresh BR sample. $\mathrm{pH}$ value was adjusted close to 0 with an appropriate amount of concentrated $\mathrm{H}_{2} \mathrm{SO}_{4}$ prior to each step. The process was repeated thrice, including the first leaching.

An agitation effect was evaluated using the options of magnetic and mechanical stirring, the latter being optionally accompanied by bottom air feed and mild bubble-agitation.

\subsection{Analytical Methods-Instrumentation}

All leaching experiments were conducted thrice, and the resulting filtered leachate was analyzed in three replicates after appropriate dilution, for Sc $(361.383 \mathrm{~nm})$ and main elements such as Fe $(259.939 \mathrm{~nm}), \mathrm{Ti}(334.940 \mathrm{~nm})$, and Si $(251.611 \mathrm{~nm})$, using ICP-OES Optima 7000DV supplied by Perkin Elmer (Waltham, MA, USA). A single standard Sc solution TraceCERT 92279 of $1000 \mathrm{mg} / \mathrm{L}$ supplied by Fluka Chemie GmbH (Buchs, Switzerland) and a multielement standard solution IV for ICP CertiPUR 1.11355 of $1000 \mathrm{mg} / \mathrm{L}$ for each element supplied by Merck KGaA (Darmstadt, Germany) were used for the preparation of working standard solutions. ICP-OES measurements were performed in axial mode for all elements after appropriate dilution. Matrix effects were taken into account by preparing standards of similar matrix. An internal standard method (Rh) was also used as a performance test. For the determination of all these elements, the calibration curve method was applied. More details about the instrument conditions, analysis parameters, and reference material can be found in [2-4]. In particular, for the determination of initial Sc in the BR batches, the reference material used was BX-N from ANRT (Association Nationale de la Recherche Technique, Paris, France).

XRD analysis of BR before and after leaching was conducted using D8 ADVANCED TWIN-TWIN with detector LYNEXEYE (1D Mode) supplied by BRUKER (Karlsruhe, Germany).

$\mathrm{pH}$ measurements were carried out by the multi $350 \mathrm{i}$ pH-meter, with a SenTix ${ }^{\circledR} 41$ precision electrode. A HeiTec magnetic stirring plate with heating and a mechanical stirrer Hei-Torque 100, both supplied by Heidolph (Schwabach, Germany), were used. High temperature experiments were performed in an autoclave bomb 4744 of a $45 \mathrm{~mL}$ capacity by Parr Instrument Company (Moline, IL, USA).

\section{Results}

Table 1 presents Sc and total REE concentrations in different Greek BR lots from the AoG production, for a period of more than 20 years, revealing for Sc a small variation of about $11 \%$. The initial Sc concentration of the BR batches used in this study was estimated at $98.0 \pm 3.0 \mu \mathrm{g}$ of $\mathrm{Sc} / \mathrm{g}$ of BR after three replicates of lithium tetraborate fusion [4]. The XRD diagrams before and after leaching with their interpretation are attached as supplementary material in Figure S1.

Table 1. Concentration $[\mathrm{g} / \mathrm{t}$ ] of $\mathrm{Sc}$ and rare earths elements (REEs) in Greek bauxite residue (BR) batches (1993-2016).

\begin{tabular}{cccccccc}
\hline Element & BR 1993 & BR 2001 & BR 2007 & BR 2012 & BR 2014 & BR 2016 & Mean \\
\hline Sc & 127.9 & 107.0 & 130.0 & 110.0 & 104.7 & 98.0 & $112.9 \pm 13.0$ \\
Total REEs & 986.1 & 868.0 & 1010.5 & 1040.3 & 729.7 & 856.0 & $915.1 \pm 118.2$ \\
\hline
\end{tabular}

\subsection{Selection of Leaching Agent}

Different mineral acids have been previously investigated as leaching agents on lab and pilot plant scales, and the obtained results are presented in Figure 1. For the lab-scale experiments, acid molarity is $0.5 \mathrm{M}$ concerning $\mathrm{HNO}_{3}, \mathrm{HCl}$, and $\mathrm{H}_{2} \mathrm{SO}_{4}$, while that for aqua regia (AQREG) is conc. $\mathrm{HCl}$ : conc. $\mathrm{HNO}_{3}, 3: 1$. In all cases, $\mathrm{S} / \mathrm{L}$ is $2 \%$ and reaction time is $24 \mathrm{~h}$. The pilot plan experiment refers to $0.5 \mathrm{M} \mathrm{HNO}_{3}$, an $\mathrm{S} / \mathrm{L}$ of $2 \%$, and a total reaction time of $60 \mathrm{~min}$. The final $\mathrm{pH}$ of the leachate is in all cases close to zero. The uncertainty of the method is estimated $\sim 7 \%$ based on the reproducibility of the results. As shown, aqua regia, followed by nitric acid, hydrochloric acid, and sulfuric acid, gives the highest recovery for Sc and the other REEs. However, the selectivity of the process shows 
the opposite trend. Co-extraction of iron and other main elements ( $\mathrm{Si}, \mathrm{Ti}$, and $\mathrm{Al}$ ) of $\mathrm{BR}$ hinder the subsequent processes of $\mathrm{Sc}$ isolation and purification. Sulfuric acid and nitric acid show the best selectivity concerning iron recovery. Although the use of nitric acid results in higher Sc recovery, sulfuric acid is preferred instead due to its mild environmental impact, which is in accordance with the EU environmental regulations for landfill disposals. Furthermore, the market price of sulfuric acid is almost half that of nitric acid, resulting in lower operating costs and enhancing the economic viability of the whole method [39-45]. Additionally, the selected agent should be at acceptable safety levels for industrial handling [19].

The leachability of other elements of techno-economical interest, such as $\mathrm{Ga}, \mathrm{Zr}$, and $\mathrm{Nb}$, is also more favored by sulfuric acid than by nitric acid [18].

Optimization of the leaching process is focused on Sc concentration rather than recovery \%, by taking into consideration the requirements of the consecutive separation and purification processes. Moreover, the leaching process economics show strong dependence between the process unit cost and Sc concentration [19].

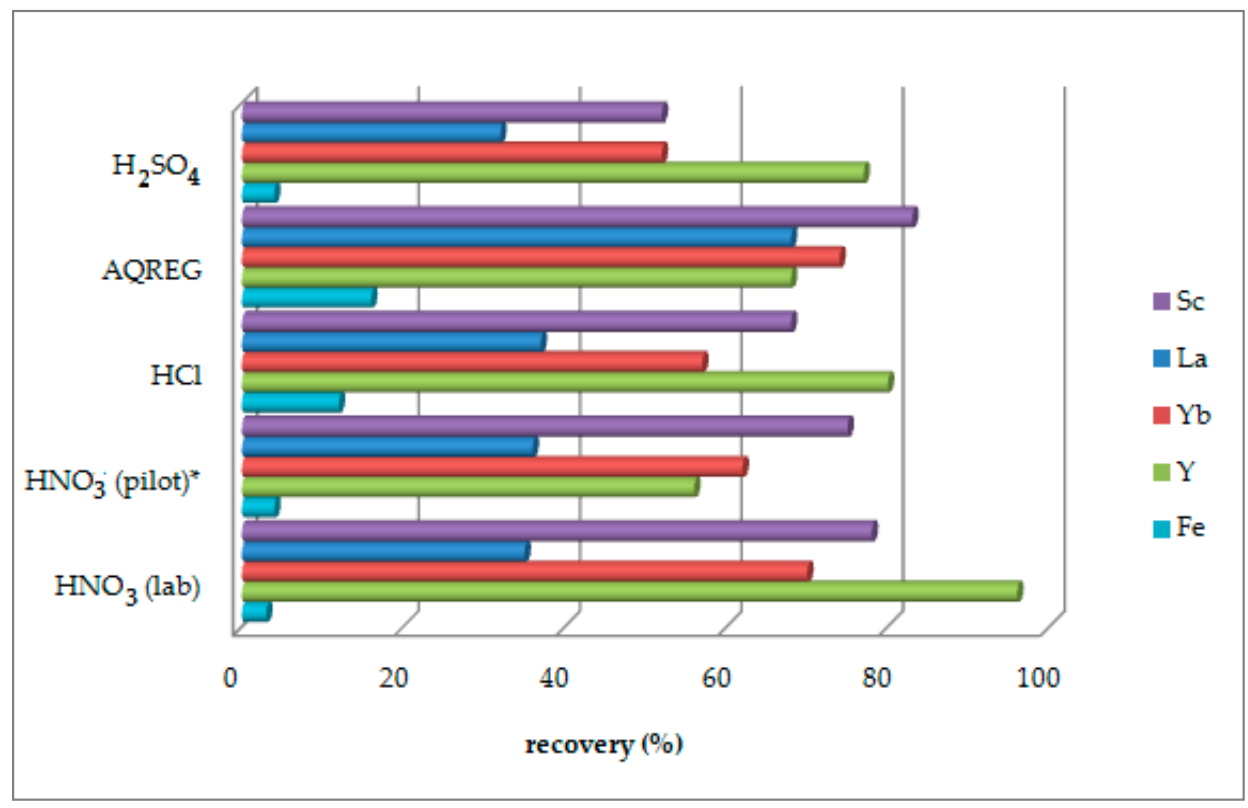

Figure 1. Recovery (\%) of Sc and other REEs by leaching with different acids (ambient conditions and a solid-to-liquid ratio (S/L) of $2 \%) .{ }^{*}$ after two successive leaching steps.

Scandium recoveries obtained by lab scale and pilot plant experiments carried out with $\mathrm{HNO}_{3}$ are quite similar, although a large-scale process might require two leaching steps due to the different dispersion conditions $[17,18,24]$.

\subsection{Effect of Leaching Time}

Leaching experiments with sulfuric acid were conducted for a prolonged period of $24 \mathrm{~h}$. The leaching reaction found to be fast and practically completed within a 60 min period. Sc concentration shows only a slight increment above $30 \mathrm{~min}$. Almost $90 \%$ of the final Sc concentration can be achieved within 10 min under higher acid molarities $(3 \mathrm{M})$. A leaching time of $60 \mathrm{~min}$ was considered for all experiments as an adequate amount of time for the completion of the reaction, justified by a relevant kinetic investigation for a sufficiently wide range of leaching conditions presented in [19]. The entire set of the relevant results is presented in Figure 2. 


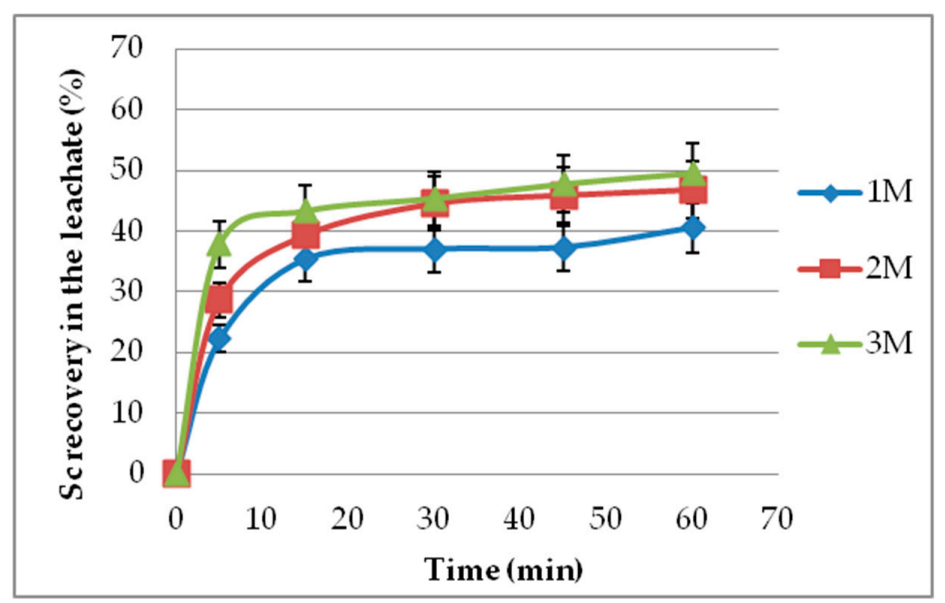

Figure 2. Leaching time effect on Sc recovery (\%) for different acid molarities and an S/L of 5\% (1:20).

\subsection{Effect of Acid Molarity}

The effect of molarity depends on S/L. Increasing molarity raises Sc concentration in the leachate, as presented in Figure 3a. Standard deviation of the method has been calculated at $\sim 7 \%$. The effect is significant for S/L values higher than $20 \%$, and the same results are also observed for iron (Figure $3 \mathrm{~b}$ ). Acid molarities higher than $3 \mathrm{M}$ were also tested and, despite the enhanced Sc concentration, were not selected due to even higher iron dissolution and reduction of process selectivity. Lower molarities are more economically viable due to lower acid consumption and environmentally friendly due to reduced acidity, ensuring the method's selectivity. On the other hand, silica gel formation occurs when low acid molarities are combined with high $\mathrm{S} / \mathrm{L}$ values. This is an important issue for hydrometallurgical processes under acidic conditions, especially for raw materials such as BR. Gel formation is caused due to the presence of silica in the solution as silicic acid $\left(\mathrm{H}_{4} \mathrm{SiO}_{4}\right)$ at $\mathrm{pH}<7$. The monomers connect to form polysilicic acid, and colloids result in gel formation, as they entrap liquid inside their structure. The use of acid molarities $>3 \mathrm{M}$ confront the problem even at high S/L values [31]. As shown in our experiments, a silicon content around $1000 \mathrm{mg} / \mathrm{L}$ is considered to be a safe threshold such that rapid gel formation is avoided. However, the method's selectivity and environmental benefits on industrial scale-up decline by increasing acid molarity. An acid molarity of $2 \mathrm{M}$ is selected as the best option to compromise these contradictory effects.

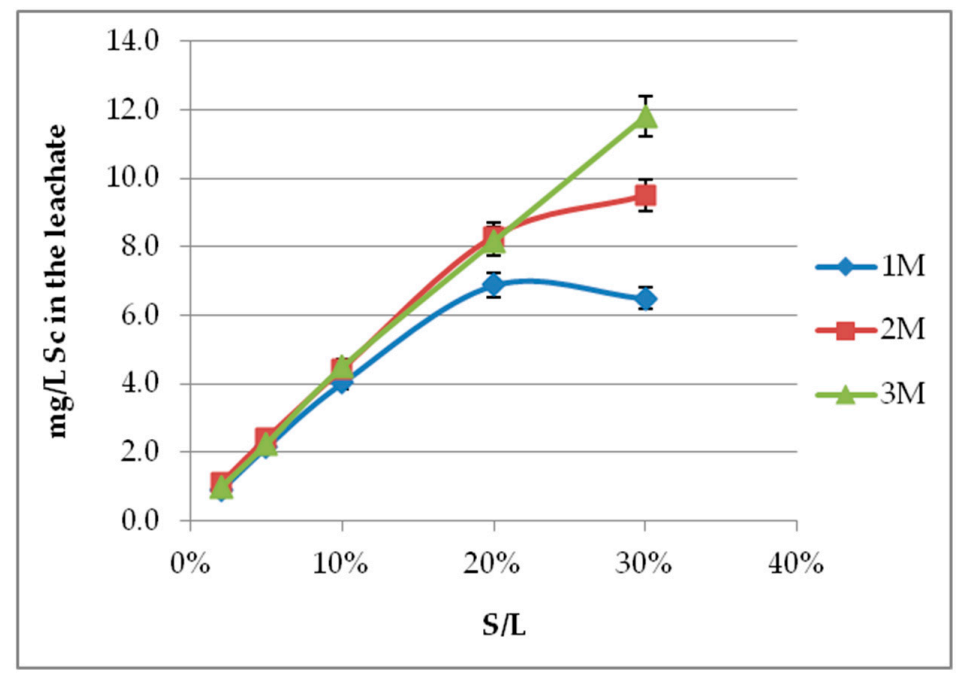

(a)

Figure 3. Cont. 


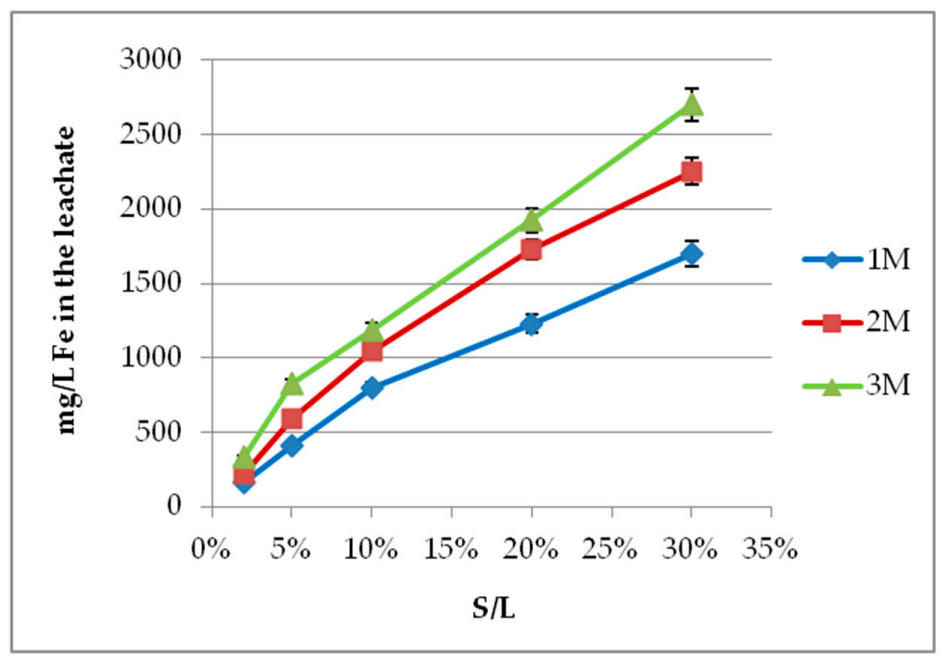

(b)

Figure 3. Acid molarity effect on (a) Sc; (b) Fe concentration for different S/L values (2-30\%) and 60 min leaching period.

\subsection{Effect of $S / L$}

Sc recovery is decreased by S/L increment, especially with low acid molarities and high S/L values, as the amount of acid is not adequate to neutralize BR, and $\mathrm{pH}$ is not adjusted (Figure 4). The essential outcome nevertheless concerns the Sc concentration in the leachate. As presented in Figure 3a, there is an almost linear correlation between S/L and Sc concentration, for all acid molarities and ratios up to $20 \%$. For ratios higher than $20 \%$, acid molarity of at least $3 \mathrm{M}$ is required to obtain sufficiently high Sc recovery in the leachate and avoid gel formation. The incapability of lower $\mathrm{H}_{2} \mathrm{SO}_{4}$ molarities to neutralize BR alkalinity at a high S/L results in high $\mathrm{pH}$ values, which do not favor leaching efficiency (see Section 3.5). The higher values of S/L induce a certain difficulty in handling of the leachate due to silica gel formation. Since the key point is the leachate's Sc concentration rather than the Sc recovery (\%), higher S/L values at appropriate molarities are preferred. The use of $2 \mathrm{M}$ $\mathrm{H}_{2} \mathrm{SO}_{4}$ combined with S/L $20 \%$ seems to be a technically acceptable compromise.

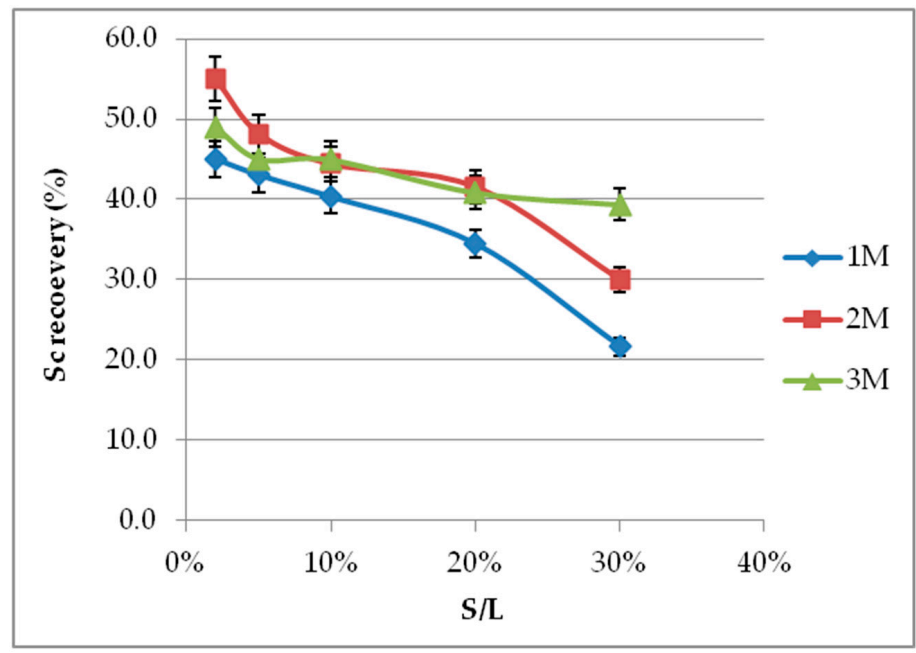

Figure 4. S/L effect on Sc recovery (\%) at different molarities and $60 \mathrm{~min}$ leaching period.

\subsection{Effect of $\mathrm{pH}$ Adjustment}

The final $\mathrm{pH}$ value of the leachate is a definite indicator of leaching process performance. A $\mathrm{pH}$ value close to 0.1 is related to a significant improvement in Sc recovery, enhanced up to $25 \%$ in 
comparison to that at higher $\mathrm{pH}$, especially in the case of high $\mathrm{S} / \mathrm{L}$ values. The set of the pertinent results is presented in Table 2. The optimum $\mathrm{pH}$ range has been found to be from 0.0 to 0.2 . Low $\mathrm{pH}$ values are considered mandatory for the increment of Sc concentration in the leachate. Furthermore, $\mathrm{pH}$ adjustment with the addition of concentrated sulfuric acid during the leaching reaction improves Sc recovery by up to $6 \%$, due to the temperature synergy effect.

Table 2. $\mathrm{pH}$ values of the leachate for different $\mathrm{S} / \mathrm{L}$ values and acid molarities ( $t=60 \mathrm{~min})$.

\begin{tabular}{cccc}
\hline S/L & M & Final $\mathbf{p H}$ & Recovery $\%$ \\
\hline $30 \%$ & 1 & 2.00 & 21.2 \\
$30 \%$ & 2 & 1.50 & 28.0 \\
$30 \%$ & 3 & 0.32 & 40.0 \\
$20 \%$ & 1 & 0.65 & 35.9 \\
$20 \%$ & 2 & 0.28 & 42.5 \\
$20 \%$ & 3 & 0.20 & 43.2 \\
$20 \%$ & pH adjusted * & 0.082 & 49.2 \\
$10 \%$ & 1 & 0.32 & 41.8 \\
$10 \%$ & 2 & 0.16 & 44.7 \\
$10 \%$ & 3 & 0.07 & 46.6 \\
$10 \%$ & pH adjusted * & 0.11 & 52.0 \\
$5 \%$ & 1 & 0.09 & 44.7 \\
$5 \%$ & 2 & 0.01 & 49.0 \\
$5 \%$ & 3 & 0.01 & 46.7 \\
\hline
\end{tabular}

$* \mathrm{pH}$ adjustment at low values about 0.1 by the addition of concentrated $96-98 \% \mathrm{w} / \mathrm{w} \mathrm{H}_{2} \mathrm{SO}_{4}$ during leaching reaction.

\subsection{Temperature Effect}

Increased reaction temperature from 25 to $80^{\circ} \mathrm{C}$ at ambient conditions, 160 and $230{ }^{\circ} \mathrm{C}$ (hotplate temperature) under autoclave conditions (see Figure $5 \mathrm{a}, \mathrm{b}$ ), improves only marginally the Sc leachability. On the other hand, iron dissolution is noticeably enhanced reaching a recovery of even $22 \%$ and a final concentration of almost $7 \mathrm{~g} / \mathrm{L}$ that diminishes method selectivity.

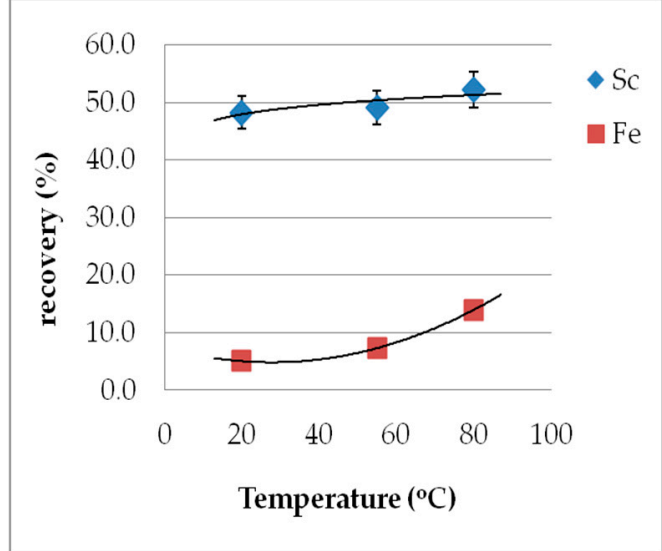

(a)

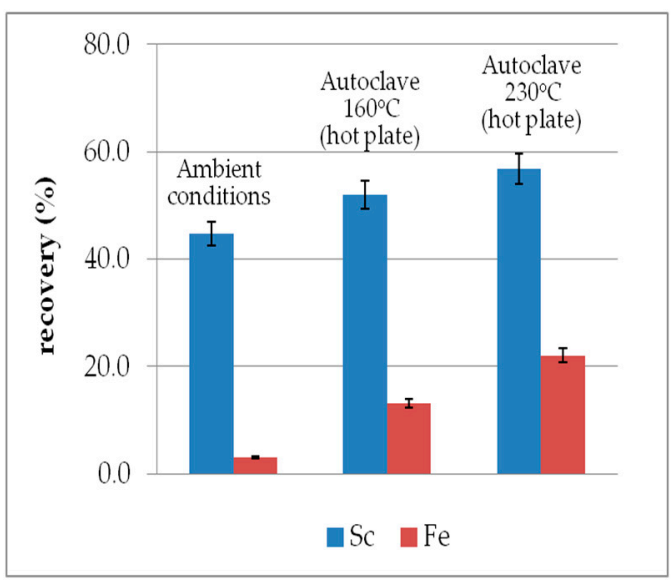

(b)

Figure 5. Effect of temperature on $\mathrm{Sc}$ and Fe recovery (a) under normal pressure and (b) under autoclave conditions (S/L 10\%, $2 \mathrm{M} \mathrm{H}_{2} \mathrm{SO}_{4}, t=60 \mathrm{~min}$ ).

Additional leaching experiments under extreme conditions were also performed in order to assess the combinatorial effect of high molarities $(>3 \mathrm{M})$ and high temperature. As expected, the results showed an essential increment both for Sc recovery (up to 70\%) and concentration (about $20 \mathrm{mg} / \mathrm{L}$ ), with avoidance of gel formation, but there was also an almost complete dissolution of iron at the expense of selectivity. Such high Fe concentration in the leachate impedes any following ion exchange 
or solvent extraction processes for Sc separation and purification. The reason lies in the chemical similarity between scandium and iron due to the close association of scandium with the microstructure of nano-perovskite in the iron oxide phases. Therefore, it is not possible to recover $100 \%$ of scandium under ambient/mild conditions [28]. Furthermore, both elements present similar hydrolysis behavior, as they are first row transition metals [46].

All above-mentioned parameters (S/L, acid molarity, temperature, and time) were also tested with respect to the concentration of other main elements. $\mathrm{Al}$ and Fe concentrations were increased by temperature, S/L, and molarity, taking values from $3000 \mathrm{mg} / \mathrm{L}$ to 13,000 mg/L and from $1040 \mathrm{mg} / \mathrm{L}$ to $32,500 \mathrm{mg} / \mathrm{L}$, respectively; Ti was increased with $\mathrm{S} / \mathrm{L}$, rising from $1430 \mathrm{mg} / \mathrm{L}$ (for 20\% S/L) to $6550 \mathrm{mg} / \mathrm{L}$ (for $40 \% \mathrm{~S} / \mathrm{L}$ ). Aluminum was not regarded as impure since Sc-Al alloys are materials of technological interest. In contrast, the silicon concentration was suppressed under almost $100 \mathrm{mg} / \mathrm{L}$ at higher molarities (>3 M), solving the silica gel formation problem.

Ambient conditions are generally more preferable, considering both the Sc selectivity and the energy consumption cost, ensuring an economically viable process design. Furthermore, Fe and Ti are of major concern in this study due to the specific requirements of the consecutive isolation and purification processes. The selectivity criteria focus on Fe content since iron oxide constitutes 50\% of BR.

\subsection{Effect of Stirring Mode}

Three kinds of stirring were tested: magnetic stirring, mechanical agitation, and mechanical agitation with air bubbles, with stirring speeds of about 550-650 rpm (see Figure 6). A standard deviation of $\sim 7 \%$ was estimated. As seen, the stirring mode has no effect on Sc concentration regardless of the S/L values and acid molarities tested. These findings apply to the lab-scale experiments of this study, but in larger scale setups more vigorous stirring conditions might be required due to diverse dispersion mechanisms.

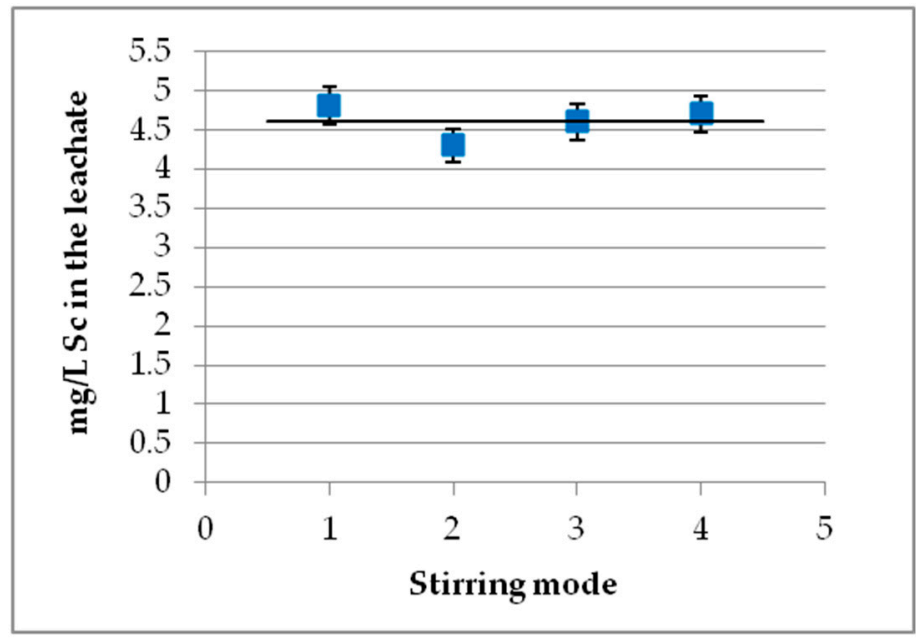

Figure 6. Effect of stirring mode (S/L 10\%, $\left.1 \mathrm{M} \mathrm{H}_{2} \mathrm{SO}_{4}, t=60 \mathrm{~min}\right) .1$. Magnetic stirring at $650 \mathrm{rpm}$; 2. mechanical agitation at $550 \mathrm{rpm} ; 3$. mechanical agitation at $650 \mathrm{rpm} ; 4$, mechanical agitation with air at $550 \mathrm{rpm}$.

\subsection{Effect of Multistage Leaching Process}

The multistage process refers to successive leaching of the same BR sample with corresponding multiple fresh sulfuric acid batches. The entire process performed in triplicates under ambient conditions for $60 \mathrm{~min}$. Different acid molarities and S/L values were studied, and the results are presented in Figure 7a,b. Multistage leaching has a positive effect on Sc recovery (Figure 7b) but causes a great reduction on Sc concentration (Figure 7a), as expected due to the obvious increment of the final leachate volume after the multiple adding of fresh sulfuric acid batches. The iron extraction remains 
relatively low even after the third stage reaching a total recovery up to $10 \%$. Despite the remarkable Sc recovery increase, the multistage process is not advantageous for large-scale applications, due to Sc concentration reduction and the required large volumes of acid feed.

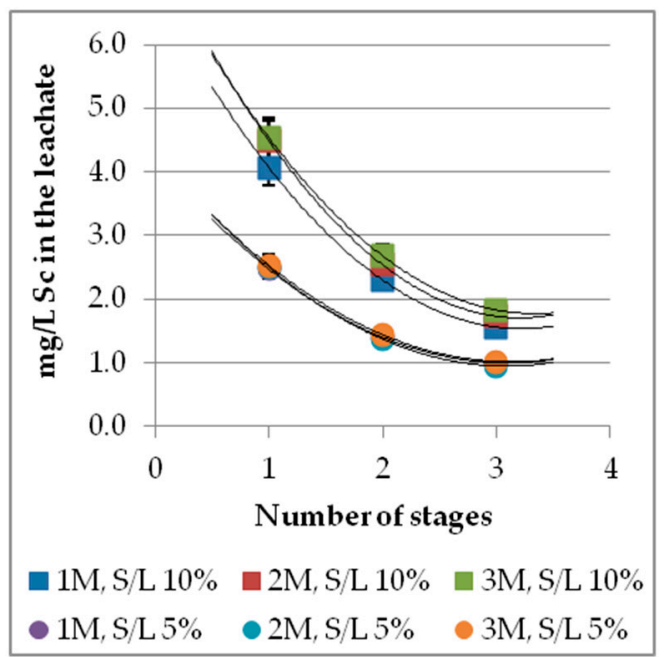

(a)

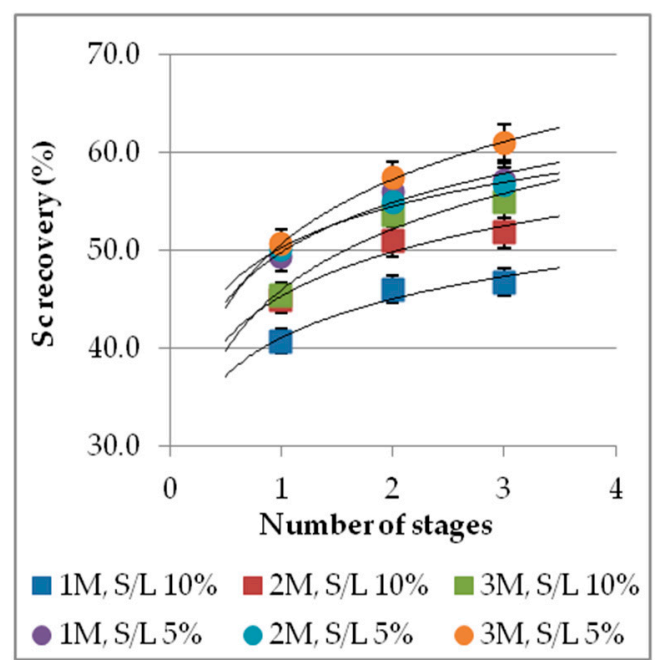

(b)

Figure 7. Multistage effect on: (a) Sc concentration; (b) Sc recovery (\%) for different acid molarities and $\mathrm{S} / \mathrm{L}$ values ( $t=60 \mathrm{~min}$, ambient conditions).

\subsection{Effect of Leachate Recycling}

The recycling process refers to multiple reusing (reflux) of the leachate on fresh BR samples. The target is threefold: (a) the leachate enrichment in Sc with the lower possible impurities in the main elements (mainly $\mathrm{Fe}$ and $\mathrm{Ti}$ ), (b) the enhancement of the leaching process' economic viability, especially on an industrial scale, and (c) the simplification of Sc further purification after leaching by ion exchange/extraction processes [15]. The entire process was performed at three sequential cycles using $1 \mathrm{M}$ and $2 \mathrm{M}$ acid molarities with additional $\mathrm{pH}$ adjustment close to zero, before each cycle. The obtained results for Sc (in $\mu \mathrm{g} / \mathrm{L}$ ), Ti, and $\mathrm{Fe}$ (in $\mathrm{mg} / \mathrm{L}$ ) for both molarities are given in Figure 8. As clearly illustrated, reusing of leachate solution thrice with combined $\mathrm{pH}$ adjustment results in almost tripled Sc concentration $(\sim 12,000 \mu \mathrm{g} / \mathrm{L})$. There is a linear correlation, with $\mathrm{R}^{2}=1.0000$ for $1 \mathrm{M} \mathrm{H}_{2} \mathrm{SO}_{4}$ and 0.9997 for $2 \mathrm{M} \mathrm{H}_{2} \mathrm{SO}_{4}$. Fe and Ti also present a linear correlation, with $\mathrm{R}^{2}=0.8712(1 \mathrm{M})-0.9999$ $(2 \mathrm{M})$ and $0.9892(1 \mathrm{M})-0.9987(2 \mathrm{M})$, respectively. However, the final concentration remains at low acceptable levels for Fe and Ti. The maximum measured Fe concentration ( 3 cycles of $2 \mathrm{M} \mathrm{H}_{2} \mathrm{SO}_{4}$ ) is $3000 \mathrm{mg} / \mathrm{L}$, corresponding to $\sim 10 \%$ recovery. Recycling of 1.5 times, which is possible in continuous operation on an industrial scale satisfies the required leachate specifications for the subsequent ion exchange process, so $\mathrm{Sc}>6 \mathrm{mg} / \mathrm{L}, \mathrm{Fe}<30,000 \mathrm{mg} / \mathrm{L}$, and $\mathrm{Ti}<1700 \mathrm{mg} / \mathrm{L}$ [15]. In addition, the leachate recycling achieves a lower acid and water consumption, promoting the viability of a large-scale application while rendering the entire process more environmentally friendly. 


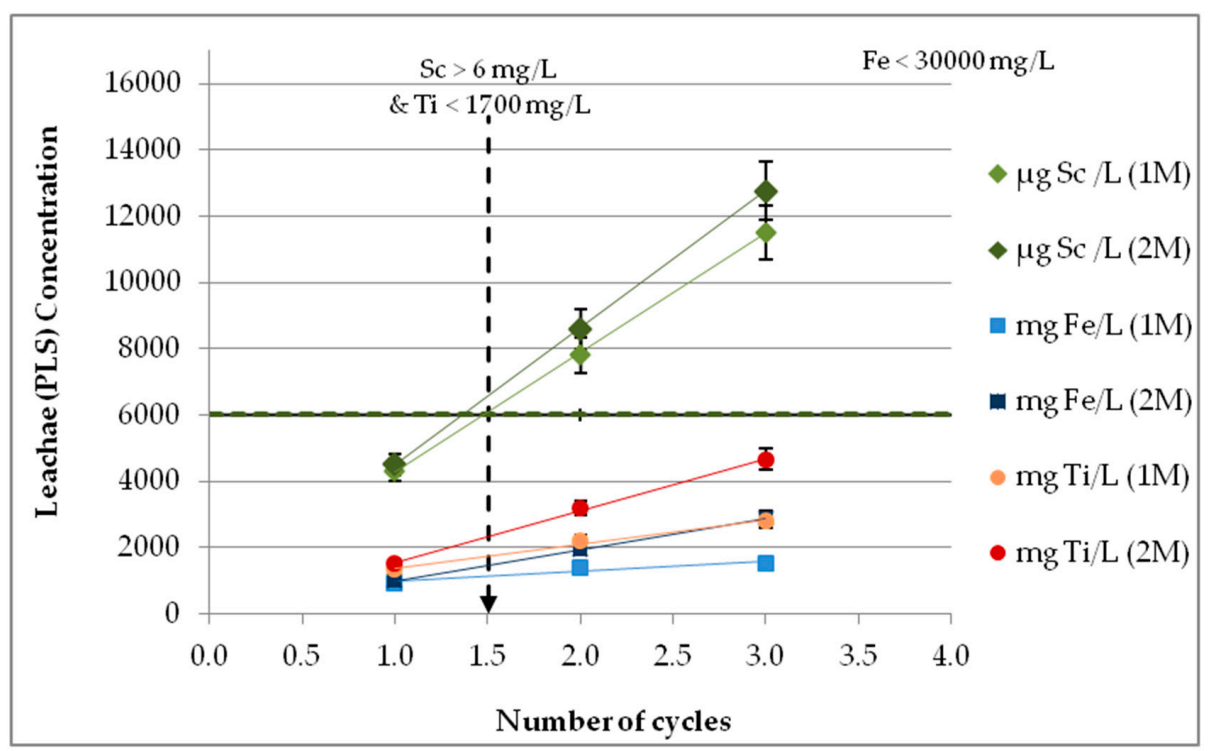

Figure 8. Leachate recycling with $\mathrm{pH}$ adjustment (S/L $10 \%, 1$ and $2 \mathrm{M} \mathrm{H}_{2} \mathrm{SO}_{4}, \mathrm{pH} \approx 0, t=60 \mathrm{~min}$, ambient conditions).

\subsection{Statistical Evaluation}

Method repeatability was evaluated by comparing the results from various leaching experiments, keeping the same research team and analytical technique, as well as the same raw material and leaching conditions. The variation of leaching efficiency is presented in Figure 9, where it is shown that the average is $42.3 \%$ with a standard deviation $\pm 2.8 \%$.

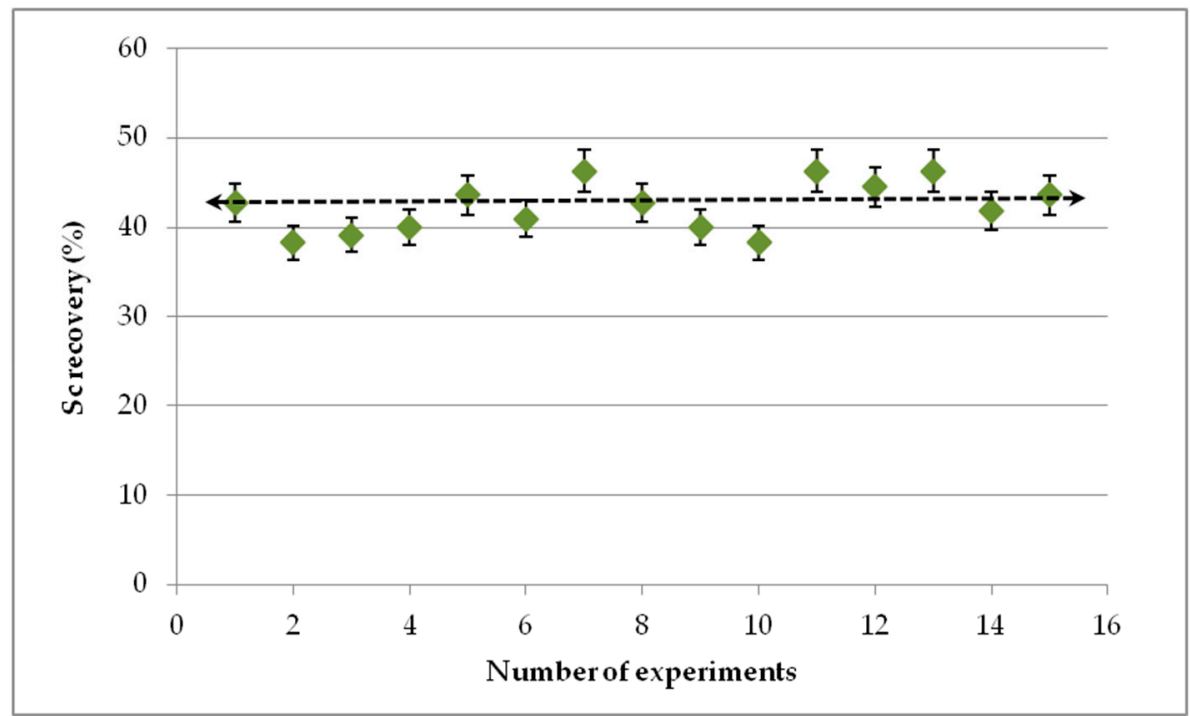

Figure 9. Repeatability of leaching process (S/L 5\%, $\left.1 \mathrm{M} \mathrm{H}_{2} \mathrm{SO}_{4}, t=60 \mathrm{~min}\right)$.

One-way ANOVA statistical analysis was applied to the experimental data in order to evaluate the contribution of each investigated parameter on Sc recovery and concentration in the leachate solution. The three independent parameters considered were time, S/L, and molarity, while the two dependent variables were recovery $\%$ and concentration. S/L has been confirmed to contribute mostly to Sc concentration, while leaching time is more critical for Sc recovery [18].

Figure 10 presents the effect of two parameters (S/L and time) on Sc concentration in the leachate solution, showing that maximum Sc concentration is achieved with a high S/L and a long leaching duration. 


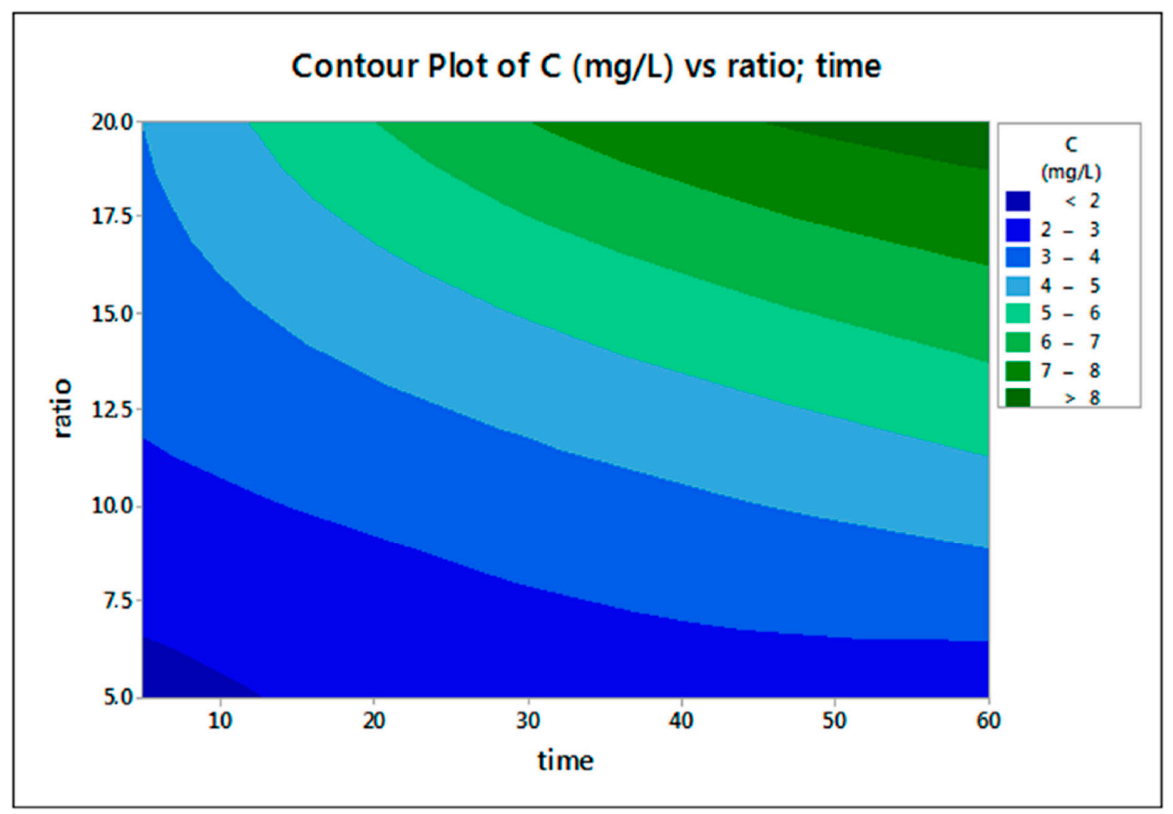

Figure 10. Two-factor (S/L and leaching time) interaction; 2D projection on the extracted Sc concentration in the leachate.

\section{Assessment and Conclusions}

The core objective of this study is to determine the optimum leaching conditions for the scale-up of the proposed process to a demonstration plant to be established in the premises of Mytilineos S.A. (the main producer of BR in Greece), taking into consideration the feed requirements of the leachate to the subsequent ion exchange process for scandium purification. This investigation expands the existing research further by introducing and studying additional parameters, such as multistage leaching, leachate recycling, $\mathrm{pH}$ adjustment of the leachate, and different stirring modes. Based on the results obtained, the development of a leaching process flow diagram (see Figure 11) was possible in order to set up a detailed blueprint for applying this method in industry.

BR leaching using $\mathrm{H}_{2} \mathrm{SO}_{4}$ at ambient conditions for Sc recovery is a rapid process, practically integrated within $30 \mathrm{~min}$. Final $\mathrm{pH}$ of the solution is critical, requiring a $\mathrm{pH}$ adjustment in the range of $0.0-0.2$. The proposed acid molarity of $2 \mathrm{M}$ is a result of a technical compromise between the higher values needed in order to avoid Si-caused gel formation $(\mathrm{Si}<1000 \mathrm{mg} / \mathrm{L})$ and the lower values that ensure Sc selectivity, mainly with respect to Fe. The S/L and leachate solution reuse are crucial for Sc concentration. A minimum of $10 \%$ slurry concentration (S/L) and a maximum of two cycles of leachate reusing are suggested, resulting under ambient conditions in an Sc concentration of about $10 \mathrm{mg} / \mathrm{L}$ and $\mathrm{Fe} 1700 \mathrm{mg} / \mathrm{L}$, corresponding to a recovery of nearly $50 \%$ and 3\%, respectively. Elevated temperature is not recommended due to high Fe dissolution at the expense of Sc selectivity. A multistage process reduces Sc concentration despite the rise of its recovery. The criteria for selecting the parameters investigated rely on environmental and process economics aspects, meaning residues of low acidity and low operating and energy cost, as well as compliance with the requirements of the consecutive Sc separation and purification processes [19].

Any further improvement depends mostly on the leachate specifications range concerning the respective separation processes after leaching (i.e., ion exchange and solvent extraction), rather than the yields of the leaching process itself. Figure 11 presents the flow diagram of the industrial scale-up of the developed leaching process followed by the purification process, based on the conceptual design for continuous operation.

The following notation is used in the above diagram: 
- $\quad \mathrm{L}=$ Leaching reactor. Indicative type: CF-CSTR (Continuous Flow-Continuous Stirred Tank Reactor), with a heating/cooling mantle to be an option.

- $\quad \mathrm{P}=$ Unit for Purification of leachate from solids. Indicative configuration: Intermediate Tank, Filter Press or Flocculator/Filters, and leachate Tank.

- $\mathrm{M}=$ Mixing unit. Indicative configuration: Continuous flow mixing device, with a heat dissipation system.

- $\quad B R=$ Bauxite Residue streams with moisture content. Subscripts: $\mathrm{i}=$ input (alkaline solids stream), $\mathrm{o}=$ output (acidic solids stream).

- $\quad \mathrm{A}=$ Acid streams (sulfuric acid solutions). Subscripts: $\mathrm{f}=$ leaching feed, $\mathrm{p}=$ product (leachate), $\mathrm{n}=$ new (fresh solution), $\mathrm{r}=$ recycling leachate, $\mathrm{d}=$ dense acid $(93-98 \% \mathrm{w} / \mathrm{w})$. (Reflux ratio) $=$ (Number of cycles in batch processing) -1 .

- $\quad \mathrm{W}=$ Water stream; mixture of raw water with used water from Filter Press cleaning.

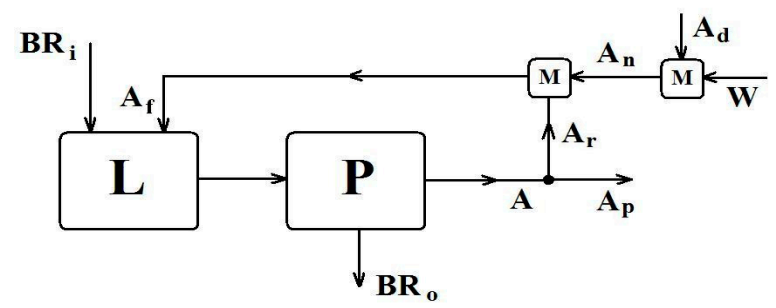

Figure 11. Conceptual design for a continuous BR leaching process.

The leaching unit solid wastes (partially neutralized $\mathrm{pH} \geq 2$ ) could be used in a pyrometallurgical unit for Fe recovery. Moreover the acidic Sc leachate $(\mathrm{pH} \approx 0)$ could be continuously forward to an ion exchanged process for further purification and the neutralized eluent could be finally recycled to the leaching unit (L, Figure 11) to cover its raw water demand.

Supplementary Materials: The following are available online at http:/ /www.mdpi.com/2075-4701/8/11/915/s1, Figure S1: Mineralogical analysis of bauxite residue before and after leaching process with sulfuric acid.

Author Contributions: This work was performed by the members of Laboratory of Inorganic and Analytical Chemistry of Department of Chemical Sciences (M.O.-P.; L.-A.T., T.L., K.-M.O., C.S., O.S., and F.T.) in collaboration with the Department of Process Analysis and Plant Design (K.H. and P.G.) of the NTUA School of Chemical Engineering. L.-A.T., T.L., C.S., and O.S. performed the experiments; T.L. and L.-A.T. integrated ICP-OES measurements; L.-A.T. and T.L. evaluated the data and wrote the draft paper; M.O.-P supervised the whole work and corrected the draft paper; K.S. designed the proposed continuous process for the future industrial scale-up; K.-M.O., P.G., and F.T. reviewed the paper.

Funding: This research was funded by the European Community's Horizon 2020 Program (H2020/2014-2020), under Grant Agreement number 730105.

Acknowledgments: The research leading to these results was performed within the SCALE project, and funding was received from the European Community's Horizon 2020 Program (H2020/2014-2020), under Grant Agreement No. 730105. The companies II-VI Inc. (Saxonburg, PA, USA) and MYTILINEOS S.A., formerly Aluminum of Greece S.A. (AoG), are also gratefully acknowledged for the fruitful collaboration and cooperation in the context of SCALE and in previous joint projects.

Conflicts of Interest: The authors declare no conflict of interest. The results of this work were derived in the context of the SCALE project (Grant Agreement No. 730105), and the publication is in accordance with its terms. The funding sponsors (EU/EASME) had no role in the design of the study, in the collection, analyses, or interpretation of data, or in the writing of the manuscript.

\section{References}

1. Power, G.; Grafe, M.; Klauber, C. Bauxite residue issues: I. current management, disposal and storage practices. Hydrometallurgy 2011, 108, 33-45. [CrossRef]

2. Ochsenkühn-Petropoulou, M.; Lyberopulu, T.; Parissakis, G. Direct determination of lanthanides yttrium and scandium in bauxites and red mud from alumina production. Anal. Chim. Acta 1994, 296, 305-313. [CrossRef] 
3. Lyberopulu, T. Determination and Recovery of Rare Earths from Bauxites and Red Mud. Ph.D. Thesis, National Technical University of Athens, Athens, Greece, 1996. Available online: https:/ / www.didaktorika. gr/eadd/handle/10442/8817 (accessed on 16 September 2018).

4. Tsakanika, L.-A. Separation and Recovery of Lanthanides from Red Mud by Use of Selective Extraction and Chromatographic Techniques. Ph.D. Thesis, National Technical University of Athens, Athens, Greece, 2013.

5. Ochsenkühn-Petropoulou, M.; Tsakanika, L.-A.; Lymperopoulou, T. Process control of an innovative method for the recovery and separation of rare earths from red mud by different analytical techniques. In Proceedings of the 1st European Rare Earth Resources Conference (ERES 2014), Milos Island, Greece, 4-7 September 2014; pp. 28-29.

6. Scandium Investing. Why Scandium Could Be a Huge Opportunity: Commercially Viable Scandium Deposits Are Rare, but There Is Indeed Opportunity in This Market. Investing News Network. 12 April 2017. Available online: http://investingnews.com/daily/resource-investing/critical-metalsinvesting/scandiuminvesting/scandium-production-the-problem-and-the-opportunity/ (accessed on 20 September 2018).

7. European Commission. Critical Raw Materials. Third List of Critical Raw Materials for the EU of 2017. Available online: https://ec.europa.eu/growth/sectors/raw-materials/specific-interest/critical_en (accessed on 20 September 2018).

8. Gambogi, J.; U.S. Geological Survey. Mineral Commodity Summaries, SCANDIUM. January 2017. Available online: https:/ / minerals.usgs.gov/minerals/pubs/commodity/scandium/mcs-2017-scand.pdf (accessed on 20 September 2018).

9. Røyset, J.; Ryum, N. Scandium in aluminium alloys. Int. Mater. Rev. 2005, 50, 19-44. [CrossRef]

10. Hildeman, G.; Koldenhoven, K. Mechanical Properties and Applications of Aluminum Scandium Alloys at Elevated Temperatures. Light Met. 2018, 1581-1587. [CrossRef]

11. Schmidtke, K.; Palma, F.; Hawkins, A.; Emmelmann, C. Process and mechanical properties: Applicability of a scandium modified al-alloy for laser additive manufacturing. Phys. Procedia 2011, 12, 369-374. [CrossRef]

12. Pan, F.; Liu, T.; Zhang, X.; Tang, A.; Wang, W. Effects of scandium addition on microstructure and mechanical properties of ZK60 alloy. Mater. Int. 2011, 21, 59-65. [CrossRef]

13. Duyvesteyn, W.P.C.; Putnam, G.F.; EMC Metals Corporation, White Paper. SCANDIUM: A Review of the Element, Its Characteristics, and Current and Emerging Commercial Applications. May 2014. Available online: http:/ / www.scandiummining.com/i/pdf/Scandium-White-PaperEMC-Website-June-2014-.pdf (accessed on 20 September 2018).

14. UC RUSAL Sustainability Report 2016. Available online: https:/ /www.unglobalcompact.org/participation/ report/cop/create-and-submit/learner/398571 (accessed on 6 November 2018).

15. Project SCALE: Production of Scandium Compounds and Scandium Aluminum Alloys from European Metallurgical by-Products. European Community's Horizon 2020 Programme. Available online: http: / / cordis.europa.eu/project/rcn/206331_en.html (accessed on 20 September 2018).

16. Awd, M.; Tenkamp, J.; Hirtler, M.; Siddique, S.H.; Bambach, M.; Walther, F. Comparison of microstructure and mechanical properties of scalmalloy®produced by selective laser melting and laser metal deposition. Materials 2018, 11, 17. [CrossRef] [PubMed]

17. Lymperopoulou, T.; Tsakanika, L.A.; Ochsenkühn, K.M.; Ochsenkühn-Petropoulou, M. Optimization of Mineral Acids Leaching Process for the Recovery of Rare Earth Elements from Greek Red Mud. In Proceedings of the 2nd Conference on European Rare Earth Resources (ERES 2017), Santorini Island, Greece, 28-31 May 2017; pp. 182-184. Available online: https://www.dropbox.com/sh/h1m9r8woixspd3f/ AABzcTZ1UXs1Ex9j0kzeleODa/ABSTRACTS/VIA/VIA1.pdf?dl=0 (accessed on 20 September 2018).

18. Ochsenkuehn-Petropoulou, M.; Lymperopoulou, T.; Tsakanika, L.A.; Ochsenkuehn, K.M.; Hatzilyberis, K.; Georgiou, P.; Stergiopoulos, C.; Tsopelas, F. Mineral Acid Leaching of Scandium from Bauxite Residue. In Proceedings of the 2nd International Bauxite Residue Valorization and Best Practices Conference (BR2018), Athens, Greece, 7-10 May 2018; pp. 373-379. Available online: http:/ /svs2015-mtm.icts.kuleuven.be/indico/ event/39/contribution/30 (accessed on 20 September 2018).

19. Hatzilyberis, K.; Lymperopoulou, T.; Tsakanika, L.-A.; Ochsenkühn, K.-M.; Georgiou, P.; Defteraios, N.; Tsopelas, F.; Ochsenkühn-Petropoulou, M. Process Design Aspects for Scandium-Selective Leaching of Bauxite Residue with Sulphuric Acid. Minerals 2018, 8, 79. [CrossRef] 
20. Mineral Prices, Rare Earth Metals. Available online: http:/ / mineralprices.com/default.aspx\#rar (accessed on 16 September 2018).

21. Liu, Z.; Li, H. Metallurgical process for valuable elements recovery from red mud-A review. Hydrometallurgy 2015, 155, 29-43. [CrossRef]

22. Wang, W.; Pranolo, Y.; Cheng, C.Y. Metallurgical processes for scandium recovery from various resources: A review. Hydrometallurgy 2011, 108, 100-108. [CrossRef]

23. Ochsenkühn-Petropulu, M.; Lyberopulu, T.; Ochsenkühn, K.M.; Parissakis, G. Recovery of lanthanides and yttrium from red mud by selective leaching. Anal. Chim. Acta 1996, 319, 249-254. [CrossRef]

24. Ochsenkühn-Petropoulou, M. Implementation and Demonstration in Pilot Unit of a New Processing Method and Use of Red Sludge, Residue of Metallurgical Process of Greek Industry (EPET II/Research Program); Final Report; Ochsenkühn-Petropoulou, M., Ed.; Laboratory of Inorganic and Analytical Chemistry, School of Chemical Engineering NTUA and Aluminium of Greece S.A.: Athens, Greece, 2001.

25. Ochsenkühn-Petropoulou, M.; Hatzilyberis, K.; Mendrinos, L.; Salmas, C. Pilot Plant Investigation of the Leaching Process for the Recovery of Scandium from Red Mud. Ind. Eng. Chem. Res. 2002, 41, 5794-5801. [CrossRef]

26. Jha, M.K.; Kumari, A.; Panda, R.; Kumar, J.R.; Yoo, K.; Lee, J.Y. Review on hydrometallurgical recovery of rare earth metals. Hydrometallurgy 2016, 165, 2-26. [CrossRef]

27. Yagmurlu, B.; Dittrich, C.; Friedrich, B. Effect of aqueous media on the recovery of scandium by selective precipitation. Metals 2018, 8, 314. [CrossRef]

28. Borra, C.R.; Pontikes, Y.; Binnemans, K.; Van Gerven, T. Leaching of rare earths from bauxite residue (red mud). Miner. Eng. 2015, 76, 20-27. [CrossRef]

29. Ujaczki, É.; Zimmermann, Y.S.; Gasser, C.A.; Molnár, M.; Feigl, V.; Lenz, M. Red mud as secondary source for critical raw materials-Extraction study. J. Chem. Technol. Biotechnol. 2017, 92, 2835-2844. [CrossRef]

30. Petrakova, O.V.; Panov, A.V.; Gorbachev, S.N.; Klimentenok, G.N.; Perestoronin, A.V.; Vishnyakov, S.E.; Anashkin, V.S. Improved efficiency of red mud processing through scandium oxide recovery. In Light Metals; Hyland, M., Ed.; Wiley: New York, NY, USA, 2015; pp. 91-96. [CrossRef]

31. Alkan, G.; Yagmurlu, B.; Cakmakoglu, S.; Hertel, T.; Kaya, Ş.; Gronen, L.; Stopic, S.; Friedrich, B. Novel Approach for Enhanced Scandium and Titanium Leaching Efficiency from Bauxite Residue with Suppressed Silica Gel Formation. Sci. Rep. 2018, 8, 5676. [CrossRef] [PubMed]

32. Bonomi, C.; Giannopoulou, I.; Panias, D. Correlation of scandium and titanium during leaching of bauxite residue (red mud) by an imidazolium ionic liquid. In Proceedings of the 2nd Conference on European Rare Earth Resources (ERES2017), Santorini Island, Greece, 28-31 May 2017. Available online: https: //www.researchgate.net/publication/321162111_CORRELATION_OF_SCANDIUM_AND_TITANIUM_ DURING_LEACHING_OF_BAUXITE_RESIDUE_RED_MUD_BY_AN_IMIDAZOLIUM_IONIC_LIQUID (accessed on 16 September 2018).

33. Davris, P.; Balomenos, E.; Panias, D.; Paspaliaris, I. Selective leaching of rare earth elements from bauxite residue (red mud), using a functionalized hydrophobic ionic liquid. Hydrometallurgy 2016, 164, 125-135. [CrossRef]

34. Qu, Y.; Lian, B. Bioleaching of rare earth and radioactive elements from red mud using Penicillium tricolor RM-10. Bioresour. Technol. 2013, 136, 16-23. [CrossRef] [PubMed]

35. Borra, C.R.; Mermans, J.; Blanpain, B.; Pontikes, Y.; Binnemans, K.; Van Gerven, T. Selective recovery of rare earths from bauxite residue by combination of sulfation, roasting and leaching. Miner. Eng. 2016, 92, 151-159. [CrossRef]

36. Borra, C.R.; Blanpain, B.; Pontikes, Y.; Binnemans, K.; Van Gerven, T. Smelting of bauxite residue (red mud) in view of iron and selective rare earths recovery. J. Sustain. Met. 2015, 2, 28-37. [CrossRef]

37. Tsakanika, L.; Ochsenkühn-Petropoulou, M.; Mendrinos, L. Investigation of the separation of Rare Earth elements from red mud by use of reversed-phase HPLC. Anal. Bioanal. Chem. 2004, 379, 796-802. [CrossRef] [PubMed]

38. Tsakanika, L.-A.; Ochsenkühn-Petropoulou, M. Separation and recovery of rare earths after red mud leaching by cation-exchange chromatography. In Proceedings of the International Bauxite Residue Valorization and Best Practices Conference (BR2015), Leuven, Belgium, 5-7 October 2015; pp. 309-315. Available online: http: / / conference2015.redmud.org/wp-content/uploads/2015/10/Lamprini-Areti-TSAKANIKAsecure.pdf (accessed on 16 September 2018). 
39. Chemical Spot Price. Available online: http://www.sunsirs.com/uk/sectors-14.html (accessed on 23 September 2018).

40. China Sulfuric Acid Price. Available online: http://www.sunsirs.com/uk/prodetail-236.html (accessed on 23 September 2018).

41. China Nitric Acid Price. Available online: http://www.sunsirs.com/uk/prodetail-723.html (accessed on 23 September 2018).

42. Industrial Sulfuric Acid Price $\mathrm{H}_{2} \mathrm{SO}_{4} 98 \%$. Available online: www.alibaba.com/product-detail/industrialSulfuric-Acid-Price-H2SO4-98-_2014682840.html?spm=a2700.7724857.normalList.26.466915ebpsz89c (accessed on 23 September 2018).

43. Industrial Grade $\mathrm{HNO}_{3}$ Liquid Nitric Acid 68\%. Available online: www.alibaba.com/product-detail/ Industrial-Grade-HNO3-Liquid-Nitric-Acid_60771810678.html?spm=a2700.7724857.normalList.38. 3eca7bb4lbng1A (accessed on 23 September 2018).

44. Sulphuric Acid 98\%. Available online: https://www.kemcore.com/catalogsearch/result/?q=sulphuric+acid (accessed on 23 September 2018).

45. Nitric Acid 68\%. Available online: https://www.kemcore.com/catalogsearch/result/?q=nitric+acid $+68 \% 25$ (accessed on 23 September 2018).

46. Aide, M.; Braden, I.; Mueller, W. Partitioning of Iron and Scandium in Soils Having Water Drainage Limitations. Appl. Environ. Soil Sci. 2009, 2009, 243482. [CrossRef]

(C) 2018 by the authors. Licensee MDPI, Basel, Switzerland. This article is an open access article distributed under the terms and conditions of the Creative Commons Attribution (CC BY) license (http://creativecommons.org/licenses/by/4.0/). 